\title{
Prevalence, Pathophysiology, Health Consequences and Treatment Options of Obesity in the Elderly: A Guideline
}

\author{
Elisabeth M.H. Mathus-Vliegen a on behalf of the Obesity Management Task \\ Force (OMTF) of the European Association for the Study of Obesity (EASO); \\ members: Arnaud Basdevant ${ }^{b}$ Nick Finer $^{c}$ Vojtech Hainer ${ }^{d}$ \\ Hans Hauner ${ }^{\mathrm{e}}$ Dragan Micic ${ }^{f}$ Maximo Maislos ${ }^{g}$ Gabriela Roman $^{\mathrm{h}}$ \\ Yves Schutz ${ }^{i}$ Constantine Tsigos ${ }^{j}$ Hermann Toplak ${ }^{k}$ Volkan Yumuk' \\ Barbara Zahorska-Markiewicz $^{\mathrm{m}}$
}

\begin{abstract}
a Department of Gastroenterology and Hepatology, Academic Medical Centre, University of Amsterdam, Amsterdam, the Netherlands, ${ }^{b}$ Department of Endocrinology, Pitié Salpêtrière Hospital; Pierre and Marie Curie-Paris 6 University, Paris, France, ' University College London Hospitals, London, UK, dObesity Management Centre, Institute of Endocrinology, Prague, Czech Republic, e Else Kröner-Fresenius-Centre for Nutrition Medicine, Technical University, Munich, Germany, ${ }^{f}$ Department for Obesity, Metabolic and Reproductive Disorders, Clinical Centre of Serbia, Faculty of Medicine, University of Belgrade, Belgrade, Serbia, ${ }^{9}$ Atherosclerosis and Metabolism Unit, Soroka UMC, Ben-Gurion University SHC, Beer Sheva, Israel, ${ }^{\mathrm{h}}$ Clinical Centre of Diabetes, Nutrition, Metabolic diseases, 'Iuliu Hatieganu' University, Cluj-Napoca, Romania, 'Department of Physiology, University of Lausanne, Lausanne, Switzerland, jDepartment of Endocrinology, HYGEIA Hospital, Athens, Greece, kDepartment of Medicine, Medical University, Graz, Austria, 'Department of Medicine, Division of Endocrinology and Metabolism, Istanbul University Cerrahpasa Medical Faculty, Istanbul, Turkey, m Department of Pathophysiology, Medical University of Silesia, Katowice, Poland
\end{abstract}

\section{Key Words}

Obesity $\cdot$ Ageing $\cdot$ Life-style interventions $\cdot$ Exercise $\cdot$ Diet $\cdot$ Pharmacotherapy $\cdot$ Bariatric surgery $\cdot$ Sarcopenia $\cdot$ Sarcopenic obesity $\cdot$ Epidemiology

\section{Abstract}

The prevalence of obesity is rising progressively, even among older age groups. By the year $2030-2035$ over $20 \%$ of the adult US population and over $25 \%$ of the Europeans will be aged 65 years and older. The predicted prevalence of obesity in Americans, 60 years and older was $37 \%$ in 2010. The predicted prevalence of obesity in Europe in 2015 varies between 20 and $30 \%$ dependent on the model used. This means 20.9 million obese $60+$ people in the USA in 2010 and 32 million obese elders in 2015 in the EU. Although cut-off values of BMI, waist circumference and percentages of fat mass have not been defined for the elderly (nor for the 
elderly of different ethnicity), it is clear from several meta-analyses that mortality and morbidity associated with overweight and obesity only increases at a BMI above $30 \mathrm{~kg} / \mathrm{m}^{2}$. Thus, treatment should only be offered to patients who are obese rather than overweight and who also have functional impairments, metabolic complications or obesity-related diseases, that can benefit from weight loss. The weight loss therapy should aim to minimize muscle and bone loss but also vigilance as regards the development of sarcopenic obesity - a combination of an unhealthy excess of body fat with a detrimental loss of muscle and fat-free mass including bone - is important in the elderly, who are vulnerable to this outcome. Life-style intervention should be the first step and consists of a diet with a $500 \mathrm{kcal}(2.1 \mathrm{MJ})$ energy deficit and an adequate intake of protein of high biological quality together with calcium and vitamin $\mathrm{D}$, behavioural therapy and multi-component exercise. Multi-component exercise includes flexibility training, balance training, aerobic exercise and resistance training. The adherence rate in most studies is around $75 \%$. Knowledge of constraints and modulators of physical inactivity should be of help to engage the elderly in physical activity. The role of pharmacotherapy and bariatric surgery in the elderly is largely unknown as in most studies people aged 65 years and older have been excluded.

Copyright (c) 2012 S. Karger GmbH, Freiburg

\section{Introduction}

In most countries there has been a rapid and continuing increase in life expectancy. By the year 2030, 20\% of the adult US population will be older than 65 years [1]. In the 27 member states of the EU, the percentage of people aged 65 years and older will rise from 17.1 in 2008 to 25.4 in 2035 and to 30 in 2060 [2]. From 2015 onwards deaths will outnumber births, and roughly 2 active people (aged 15-65 years) will be caring for one inactive older person. This increase in life expectancy, however, does not necessarily mean an increase in healthy life years but rather in extra years of illness proneness and chronic ill health. These demographics, together with the increased prevalence and severity of obesity which show an upward shift into older ages, signifies a double disease burden for the future. Obesity in the elderly (here defined as age $\geq 65$ years unless otherwise stated) is thus an issue of serious concern [3].

\section{Prevalence of Obesity in the Elderly}

The prevalence of obesity is rising progressively, even among older age groups. In Europe, the prevalence of obesity increases with age to peak at about 60 years. Thereafter, body weights change little and begin to decline in older age. However, current trends indicate that the prevalence of obesity in this age group will increase. The Scottish Health Survey, for example, has recently shown that in the 10 years between 1998 and 2008, while the overall prevalence of obesity showed little increase, the BMI continued to rise between the age of 60 and 70, especially in women [1]. In that same period, waist circumference showed a 5-10 $\mathrm{cm}$ increase in both sexes at ages between 50 and 70 years. This disproportionate increase in waist circumference with a smaller increase in BMI in the Scottish Health Survey may indicate an unfortunate circumstance of gain in visceral fat mass and loss of lean tissue which are both major determining factors of ill health in the obese elderly. In France, the ObEpi survey 1997-2006 analysed the obesity prevalence with age, period and cohort as explanatory variables [4]. In those aged $\geq 65$ years the prevalence of obesity was $17.9 \%$ and similar in both sexes. Severe or stage III obesity (BMI $\geq 40 \mathrm{~kg} / \mathrm{m}^{2}$ ) was present in $1.1 \%$. 
With older age obesity prevalence decreased from $19.5 \%$ in those aged $65-69$ years to $13.2 \%$ in those aged over 80 years. An increased waist circumference, $\geq 102 \mathrm{~cm}$ in males and $\geq 88 \mathrm{~cm}$ in females, was present in $47.6 \%$ of subjects. An alarming finding in the ObEpi study is the acceleration in the prevalence of obesity for individuals born after the mid1960 s. In Spain, $35 \%$ of subjects aged $\geq 65$ years suffered from obesity ( $30.6 \%$ of males and $38.3 \%$ of females) and $61.6 \%$ had an increased waist circumference (50.9\% of males $\geq 102$ $\mathrm{cm}$ and $69.7 \%$ of females $\geq 88 \mathrm{~cm}$ ) [5]. Severe or stage III obesity was present in $1.2 \%$. In the Netherlands, obesity was present in $18 \%$ of males and $20 \%$ of females $\geq 60$ years of age, whereas $40 \%$ of males and $56 \%$ of females had an increased waist circumference $(\geq 102 \mathrm{~cm}$ for males and $\geq 88 \mathrm{~cm}$ for females) [6]. The European Prospective Investigation on Cancer and Nutrition (EPIC), with participants aged 40-65 years in 1996, predicted a prevalence of obesity of about $30 \%$ in 2015 in a linear prediction model and of about $20 \%$ in a levelling off model [7].

In the USA, it was estimated that the prevalence of obesity (BMI $\geq 30 \mathrm{~kg} / \mathrm{m}^{2}$ ) in elderly Americans, aged 60 years and older, would increase from $23.6 \%$ in 1990 and $32.0 \%$ in 2000 to $37.4 \%$ in 2010 (ranging from 33.6\% in the best-case estimate to 39.6\% in the worst-case estimate) [8]. This signifies an increase in the number of obese older adults from 9.9 million (1990) and 14.6 million (2000) to 20.9 million in 2010 (range 18.0-22.2 million). The Behavioural Risk Factor Surveillance System (BRFSS) provided data on 52,921 subjects aged 65 years and older, $20.3 \%$ of whom were classified as being obese [9]. In the age group 65-74 years, $25 \%$ had a BMI $\geq 30 \mathrm{~kg} / \mathrm{m}^{2}$ which was significantly more than the $16.6 \%$ prevalence in the 75 - to 84 -year age group and the $9.9 \%$ prevalence in the $\geq 85$-year age group. Birth cohort analyses of the successive waves of the National Health and Nutrition Survey 19712002 showed that members of the 'baby boom' generation (born 1946-1965) were more obese and became so at younger ages than their predecessors (the 'silent' generation, born 1926-1945) [10]. When the 'silent' generation were aged 35-44 years, 14-18\% were obese. At comparable ages, 28-32\% of the 'baby boom' generation were obese. By 2030 , the last of the 'baby boom' generation will turn 65 years old.

The obesity prevalence in nursing homes is also already a common problem [5]. A multistate study of newly admitted nursing home residents found an alarming $30 \%$ of adults aged 65 years and older to have a BMI of $35 \mathrm{~kg} / \mathrm{m}^{2}$ or greater [6]. Almost $30 \%$ of US nursing homes reported that $15-20 \%$ of the residents within the nursing homes were obese. Evidence suggests that obesity and weight gain increase the relative risk of nursing home admission for community-dwelling older adults. For those aged 65-74 years, the risk of admission increased by $31 \%$ [7]. Those who were overweight and experienced a significant weight gain were two times as likely to be admitted to a nursing home [8].

- Obesity in the elderly will be an increasing problem

- Baby boom members became obese at earlier age and are more obese than their predecessors

- The acceleration in the prevalence of obesity for individuals born after the mid-1960s is alarming

- Obesity prevalence rates defined by waist circumference are higher than those defined by BMI in the elderly.

\section{Pathophysiology of Obesity in the Elderly}

Ageing is associated with important changes in body composition and metabolism [1114]. Between the age of 20 and 70 years, there is a progressive decrease of fat-free mass (mainly muscle) of about $40 \%$ and a rise in fat mass. There is a relatively greater decrease in peripheral compared to central fat-free mass. After the age of 70 years, fat-free mass and 
fat mass decrease in parallel. Fat distribution changes with age such that there is an increase in visceral fat, which is more marked in women than in men. Also, fat is increasingly deposited in skeletal muscle and in the liver. The higher visceral fat is the main determinant of impaired glucose tolerance in the elderly. Increased intramuscular and intrahepatic fat contribute to impaired insulin action through locally released adipokines and free fatty acids. Increased pancreatic fat with declining $\beta$-cell function also plays a role [15].

Due to the loss of skeletal muscle, the basal metabolic rate declines by $2-3 \%$ per decade after the age of 20 years, by $4 \%$ per decade after the age of 50 years, equating approximately $150 \mathrm{kcal}(630 \mathrm{~kJ})$ per day, and overall by $30 \%$ between the age of 20 and 70 years [16]. This, together with decreased intensity and duration of physical activity as well as decreased postprandial energy expenditure due to a decreased fat oxidation, accounts for the decreased energy expenditure seen with ageing.

Both obesity and ageing are characterised by a low-grade inflammatory state and by endocrine changes. Central and visceral fat depots produce more pro-inflammatory adipokines than subcutaneous fat depots, increasing the inflammatory load [17]. The low-grade inflammatory state leads to loss of lean body mass, reduced immune function, cognitive decline, accelerated atherosclerosis and insulin resistance. Indeed, many of the inflammatory molecules that are overproduced, such as TNF- $\alpha$ and IL-6, have catabolic effects on muscle mass and are involved in sarcopenia, a steady and involuntary loss of skeletal muscle mass with ageing resulting in decreased physical performance, mobility disability and frailty $[11,12,18-20]$.

Endocrine changes related to obesity in the elderly include decreased oestrogen levels (females), decreased total testosterone (females and males) and free testosterone (males) levels, decreased sex hormone binding globulin (SHBG) and dihydroepiandrosterone (DHEA) levels, increased prolactin and cortisol levels, changes in thyroid hormones (increased free T4 and reversed T3 and decreased T3 levels), and secondary hyperparathyroidism in the presence of low vitamin D levels $[11,21]$. Decreased growth hormone and insulin-like growth factor-1 (IGF-1), leptin and insulin resistance, and down-regulation of ghrelin are also present. These hormonal changes that occur with normal ageing seem to be exaggerated in the presence of abdominal obesity and insulin resistance [11].

- The important changes in body composition and metabolism by ageing add unfavourably to the obese state

- Both obesity and ageing are characterised by a low-grade inflammatory state and endocrine changes

- The health consequences of obesity in the elderly are largely explained by the decrease of peripheral lean mass, the increase in visceral fat and the deposition of fat in muscles, liver and pancreas.

\section{Health Consequences of Obesity in the Elderly}

It is far from clear which measure of adiposity best predicts the impact of obesity on health outcomes in the elderly. BMI, which correlates with body fat in the young and middleaged, can either underestimate the degree of fatness in older people because of changes in body composition or overestimate it due to loss of height from vertebral compression and kyphosis. So, the relationship between BMI and disease risk is much weaker in the elderly than in younger people. There are no data to define an optimal BMI and therefore no data on lower definitions for overweight and obesity in the elderly of different ethnicity. Moreover, the effect of ageing on body fat distribution (increased omental, mesenteric, intramuscular 
and intrahepatic fat deposition) increases the risk of insulin resistance. Waist circumference, which correlates highly with total fat and intra-abdominal fat, might better predict adverse health effects of obesity in the elderly but there are insufficient data to define appropriate cut-off values for the elderly.

The National Institute of Health (NIH) guidelines, published in 1998, suggested that a 70 -year-old person with a weight of $64 \mathrm{~kg}$ and a height of $1.6 \mathrm{~m}\left(\mathrm{BMI} 25 \mathrm{~kg} / \mathrm{m}^{2}\right)$ and at least one additional risk factor (such as established coronary heart disease, hypertension, impaired glucose tolerance, dyslipidaemia etc.) would be a candidate for weight loss [22]. This was questioned by Heiat et al. [23] in 2001 and by Janssen and Mark in 2007 [24]. Heiat et al. [23] reviewed 13 articles that reported the association between BMI and all-cause and cardiovascular mortality in non-hospitalised subjects over 65 years of age with a follow-up of more than 3 years. They did not find support for overweight conferring an excess mortality risk and found a small relative mortality risk in higher BMI ranges (a relative risk (RR) of $1.15-1.34$ with BMI $28-29 \mathrm{~kg} / \mathrm{m}^{2}$ and a RR of $1.31-2.0$ with BMI $30-35 \mathrm{~kg} / \mathrm{m}^{2}$ ). The relation between BMI and all-cause mortality was described as a U-shaped curve with a large flat bottom and a right curve that started to rise from a BMI $>31-32 \mathrm{~kg} / \mathrm{m}^{2}$. Janssen and Mark [24] performed a meta-analysis of 28 articles on the association of BMI and all-cause mortality in subjects 65 years and older with a follow-up of at least 1 year. They found that a BMI in the overweight range was not associated with an increased risk and that a BMI in the moderately obese range carried a modest increased risk (risk estimate $1.10(1.06 / 1.13)$ ), which was marginally higher for women (risk estimate 1.18 (1.13/1.24) vs. 1.10 (1.02/1.18) in men)). So, the threshold value at which BMI confers mortality risk is higher in the elderly than in younger adults. Longitudinal studies published after these meta-analyses have confirmed this [25-29].

In the presence of certain diseases a higher BMI has even be found to be protective (the 'obesity paradox') [30, 31].

Although a higher BMI value predicts a lower relative mortality in older adults, it should not mask the harm from obesity to the elderly. While the relative risk of mortality seems to decrease at ages above 59 years, the absolute mortality risk increases with increasing BMI till the age of 75 years $[13,14,32]$. Additional confounding factors contribute to underestimating the health risks of obesity in the elderly and the obesity paradox [12]. These include the survival effect (the presence of 'resistant' survivors in whom the relation between BMI and mortality is lost), competing mortalities, relatively shortened life expectancy in the old age and the importance of age of onset and duration of obesity, as those who became obese in old age may die before the adverse effects of obesity become apparent. Also, smoking, weight change (weight gain and weight loss may be more detrimental than stable weight) and unintentional weight loss may confound the estimation of health risks. The underlying disease (reverse causation), physical activity and cardiorespiratory fitness (a lean unfit may have a higher mortality than an obese fit subject), fat distribution (unknown in many studies) and length of follow-up (as with shorter duration no association between obesity and mortality is evident) also play a role $[12,28]$. Thus, the inverse relation between BMI and mortality (the obesity paradox) observed in a recent study of US veterans aged 40-70 years at entry could be explained by some of these factors: reverse causation, veteran effect (becoming obese after discharge from the service), survival effect and being a healthy obese [29]. Furthermore, the high fitness state despite a high BMI may have biased the generalisability of these findings [28, 29, 33].

Medical complications of obesity in the elderly are mainly concentrated around the metabolic syndrome (with glucose intolerance, hypertension, dyslipidaemia and cardiovascular disease). The metabolic syndrome peaks at the age of 50-70 years in males and of 60-80 years in females with an odds ratio (OR) of 5.8 in 65-year-old males and 4.9 in 
65-year-old females compared to 20- to 34-year-old subjects [34]. The metabolic syndrome is a recognised risk factor for stroke, but is also related to subclinical ischaemic brain lesions, placing the subjects at risk for future cognitive impairment [35]. A recent meta-analysis suggests the existence of a significant U-shaped association between BMI and Alzheimer's disease and vascular dementia [36, 37]. Obesity also increases the risk of heart failure, and estimates suggest that having a BMI $\geq 30 \mathrm{~kg} / \mathrm{m}^{2}$ doubles the risk [38]. Increased waist circumference and percentage body fat also predicted this risk [39]. Other obesity-related disorders are osteo-arthritis (with an OR of 4.8 for males and 4.0 for females), pulmonary dysfunction including the obesity hypoventilation syndrome and obstructive sleep apnoea syndrome, certain cancer types, reduced cognitive skills, sexual dysfunction and urinary incontinence $[1,10,14,32,40-42]$. Obesity may also contribute to cataract formation and the progression of age-related macular degeneration.

The obese elderly are also likely to have functional limitations because of decreased muscle mass and strength and increased joint dysfunction, disabilities of activities of daily living, frailty, chronic pain and impaired quality of life $[1,14,43,44]$. Unintentional injuries such as sprains and strains occur more often [45]. Obesity is an important risk for frailty either through increased levels of inflammatory markers or through sarcopenia (OR 3.5 in 70- to 79-year-old females) [46].

At the same time, however, obesity can have beneficial effects (through endocrine effects of insulin, leptin and oestrogens on stimulating bone growth and inhibiting bone remodelling) that can result in preserved or higher bone mineral density, a lower risk of osteoporosis and hip fractures as well as a cushioning effect of fat around the trochanter that can provide protection against hip fracture during a fall.

- It is as yet unknown which measure (BMI, waist circumference, percentage body fat, visceral fat mass) and which cut-off value predicts best the health risks in the obese elderly

- Anthropometric values for defining obesity in elderly ethnic groups are not defined

- The threshold value at which BMI confers mortality risk is higher in the elderly than for younger adults (BMI $\left.\geq 30 \mathrm{~kg} / \mathrm{m}^{2}\right)$

- While the relative risk of mortality and decreased survival seem to decrease at ages above 60 years, the absolute mortality risk increases with increasing BMI till age 75 years

- Many confounding factors contribute to underestimating the health risks of obesity in the elderly and to the obesity paradox

- Besides the metabolic syndrome, obesity in the elderly is characterised by functional limitations, osteo-arthritis, reduced cognitive skills, decreased visual function, dementia and impaired pulmonary function

- Increased bone mineral density and a cushioning effect of fat around the hips protect against fractures.

\section{Who Should Lose Weight and What Are the Concerns?}

The considerations above do not directly inform about the risks or benefits of intentional, therapeutic weight loss. Few data (outside of bariatric surgery) provide long-term prospective outcome data even in the young and middle-aged; there are very few data in the elderly. However, recent analysis of the Sibutramine Cardiovascular Outcome Trial (SCOUT) (which included many elderly subjects (mean age 63 years), all of whom had a history of cardiovascular disease and/or diabetes and were treated with diet, lifestyle and sibutramine or placebo) showed reduced vascular outcome events and mortality with weight loss, achieved in the first 6 weeks or 1 year [47]. 
Table 1. Potential benefits and risks related to weight loss in the elderly [48]

\begin{tabular}{ll}
\hline Benefits & Risks \\
\hline $\begin{array}{l}\text { Reduced risk for developing type 2 diabetes in subjects } \\
\text { with impaired glucose tolerance }\end{array}$ & $\begin{array}{l}\text { Potentially increased mortality risk with unin- } \\
\text { tentional weight loss and less with intentional } \\
\text { weight loss }\end{array}$ \\
\hline $\begin{array}{l}\text { Improved glycaemic, lipid and blood pressure control, } \\
\text { reduced cardiovascular risk }\end{array}$ & $\begin{array}{l}\text { Loss of muscle mass (sarcopenia) if not com- } \\
\text { bined with regular exercise }\end{array}$ \\
\hline $\begin{array}{l}\text { Possibly reduced mortality risk from cardiovascular } \\
\text { disease with intentional weight loss }\end{array}$ & $\begin{array}{l}\text { Loss of mineral bone density, osteoporosis, and } \\
\text { increased risk of fractures }\end{array}$ \\
\hline $\begin{array}{l}\text { Improved respiratory function and obstructive sleep } \\
\text { apnoea control }\end{array}$ & $\begin{array}{l}\text { Increased risk of specific protein and vitamin } \\
\text { deficiencies }\end{array}$ \\
$\begin{array}{l}\text { Improved functional capacity and ability of activities of } \\
\text { daily living, reduced musculoskeletal co-morbidities }\end{array}$ & $\begin{array}{l}\text { Increased risk of gallstone formation and chole- } \\
\text { cystitis (only in rapid weight loss) }\end{array}$ \\
\hline
\end{tabular}

Improved depressive symptoms, sense of well-being and quality of life

In 2005, the American Society of Nutrition and the North American Association for the Study of Obesity revised the NIH guidelines of 1998 [13, 14, 22]. Adverse effects of intentional weight loss (such as the loss of bone and muscle mass) may influence the risk:benefit ratio (table 1, fig. 1) [48]. In the non-overweight elderly, weight loss and a decrease in fat mass have been associated with an increased risk of hip fractures $[49,50]$. In young adults $75 \%$ of diet-induced weight loss is composed of fat tissue and $25 \%$ is composed of fat-free tissue, and this does not appear to be different in the elderly [51,52]. This moderate loss of lean body mass has not been thought relevant in obese subjects who not only have more fat mass, but also more muscle mass, needed to support the body and to enable movements and physical exercise with a heavier body weight. However, a specific condition in the elderly has been described that may contradict this reassurance. The term 'sarcopenic obesity' was coined in 2004 by Roubenoff [53] to characterise the confluence of excess fat co-existing with low lean body mass including both muscle and bone $[19,53,54]$. In sarcopenic obesity, the proportion of muscle mass is low relative to the total weight. There is a loss of muscle quantity and quality with decreased number and size of muscle fibres, reduced mitochondrial function and decreased synthesis of muscle protein. These changes result in decreased functional capacity and quality of life, increased risk of disability, morbidity and mortality, and increased risk of frailty, falls and loss of independency. On the one hand, the pro-inflammatory cytokines TNF- $\alpha$ and IL- 6 produced in adipose tissue stimulate the degradation of protein and induce muscle wasting; on the other hand, both sarcopenia and obesity are associated with a decrease in anabolic hormones such as testosterone and IGF-1 [11, 19, 21, 54].

Thus, obesity and sarcopenia in the elderly may potentiate each other, maximising their effects on disability and morbidity. Baumgartner et al. [55] demonstrated that obesity and sarcopenia were each strongly associated with disability (OR of obesity: 1.34 in males and 2.15 in females; OR of sarcopenia: 3.78 in males and 2.96 in females) but both combined were more strongly associated than either alone (OR 8.72 in males and OR 11.98 in females). 


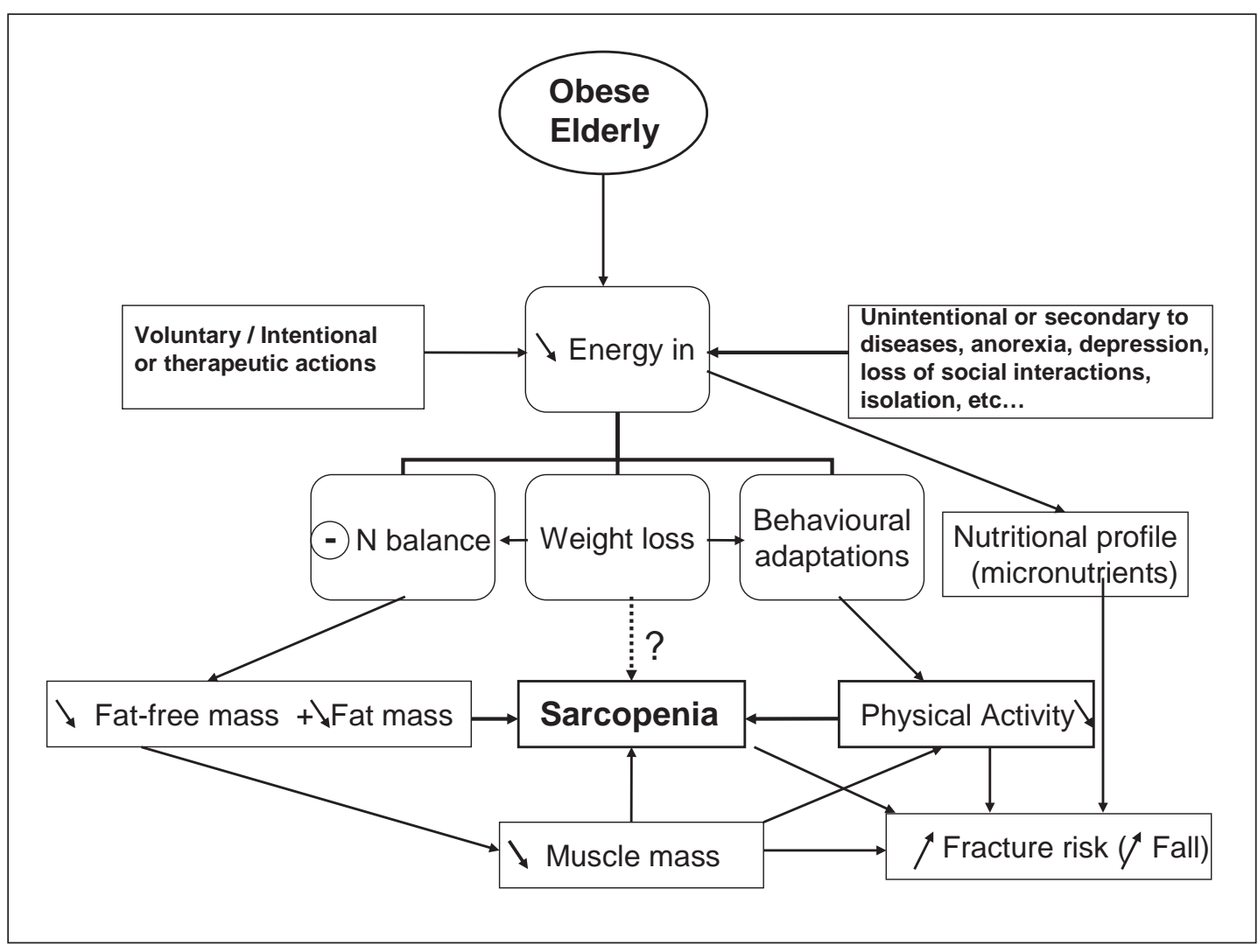

Fig. 1. Negative energy balance (intentional or not) and the potential health consequences from consequent weight loss in elderly obese subjects.

The hazard ratio of a drop in two instrumental activities of daily living (IADL) over a 7-year follow-up period in the presence of sarcopenic obesity was 2.5-3.0, and this drop of two IADLs was associated with a more than 5 times higher mortality (28.6 vs. $5.6 \%)$ in the short term (1.5 vs. 2.3 years). These measures of physical capacity were self-reported. Bouchard et al. [56] measured objectively the physical capacity in almost 900 subjects $68-82$ years old. Obesity per se appeared to contribute more to a lower physical capacity than sarcopenia.

Identification of elderly subjects with sarcopenic obesity is clinically relevant but difficult. Muscle strength is more important than muscle mass as a determinant of functional limitation and poor health. Measuring muscle strength (handgrip dynamometry) is easier, cheaper and clinically more relevant than measuring muscle mass (by DEXA, CT scan or bioelectrical impedance analysis). In studies using muscle mass as an indicator of sarcopenia, the prevalence of sarcopenia ranges from 4 to $12 \%$ [57, 58]. Based on BMI and handgrip strength sarcopenic obesity can be roughly estimated between 4 and $9 \%$.

So, weight loss recommendations should be restricted to elderly patients who are obese and who have functional limitations or metabolic complications that may benefit from weight loss by a weight loss therapy that minimises muscle and bone loss $[11,13,14]$. Assessment of body composition is particularly important in determining if an older individual will benefit from intentional weight loss. It may also safeguard against excessive lean body mass loss. 
- Weight loss is recommended in the elderly only in case of obesity $\left(B M I \geq 30 \mathrm{~kg} / \mathrm{m}^{2}\right)$ combined with weight-related co-morbidities or functional limitations that may benefit from weight loss

- Adverse effects include the risk of (aggravation of) sarcopenic obesity (the unfavourable combination of excess total body and visceral fat mass with the age-related reduction in skeletal muscle mass) and the loss of bone density and risk of hip fractures

- The identification of subjects with sarcopenic obesity is difficult.

\section{Treatment Options in the Elderly}

Obesity-related complications such as diabetes, hyperlipidaemia and hypertension should be treated but this treatment may need adapting for age (e.g. pharmacokinetic considerations relating to declining renal or hepatic functions). The current therapeutic tools available for weight management in the elderly do not differ from those for weight management in general and include: life-style intervention involving diet, physical activity and behavioural modification, pharmacotherapy and surgery (fig. 2) [13, 14].

\section{Life-Style Intervention}

Increased physical activity and regular exercise are not essential for achieving initial weight loss but help to preserve lean body mass, maintain weight loss and prevent weight regain. Elements of aerobic exercise, resistance training, balance and flexibility training may be of particular benefit in older persons because it improves physical function and frailty. Behavioural therapy includes self-monitoring, goal setting, social support, stimulus control and relapse prevention.

The combination of a moderate energy-deficit diet, increased physical activity and behavioural modification results in moderate weight loss of $0.4-0.9 \mathrm{~kg} /$ week or $8-10 \%$ after 6 months, improved obesity-related medical complications and physical dysfunction with a small risk of treatment-associated complications [13, 14].

Evaluating the efficacy of life-style interventions must come from studies that specifically include only or at least a large number of elderly subjects. In the Diabetes Prevention Program, obese men and women up to the age of 84 years were included to follow a programme of moderate physical activity of at least $2.5 \mathrm{~h}$ a week and a reduction in total dietary fat to less than $25 \%$ of total energy, coupled with sessions with a life-style counsellor [59]. Every kilogram of weight loss through diet and exercise reduced the incidence of type 2 diabetes by $16 \%$ over a period of 3.2 years and by 3.3 cases per 100 -patient years in the 60- to 85-year-age group, half of that obtained in the younger age group of 25-44 years of age. Systematic reviews of weight loss interventions in people aged over 60 years revealed significant improvements in glucose tolerance and physical functioning, a reduced incidence of diabetes and significant benefits for those with osteo-arthritis, diabetes and coronary heart disease (table 1) [41, 48,60]. Negative outcomes included slightly decreased bone mineral density and lean body mass. Research has tended to focus excessively on cardiovascular risks but insufficiently on the multiple effects of obesity on mobility, bladder function, sexual health, mood and quality of life which determine the everyday life of the elderly [1].

\section{Life-Style Intervention: Is It Feasible in the Frail Elderly?}

Changing the life-style of older persons presents special challenges. An increased burden of disease, adverse quality of life, cognitive dysfunction and depression, isolation, 


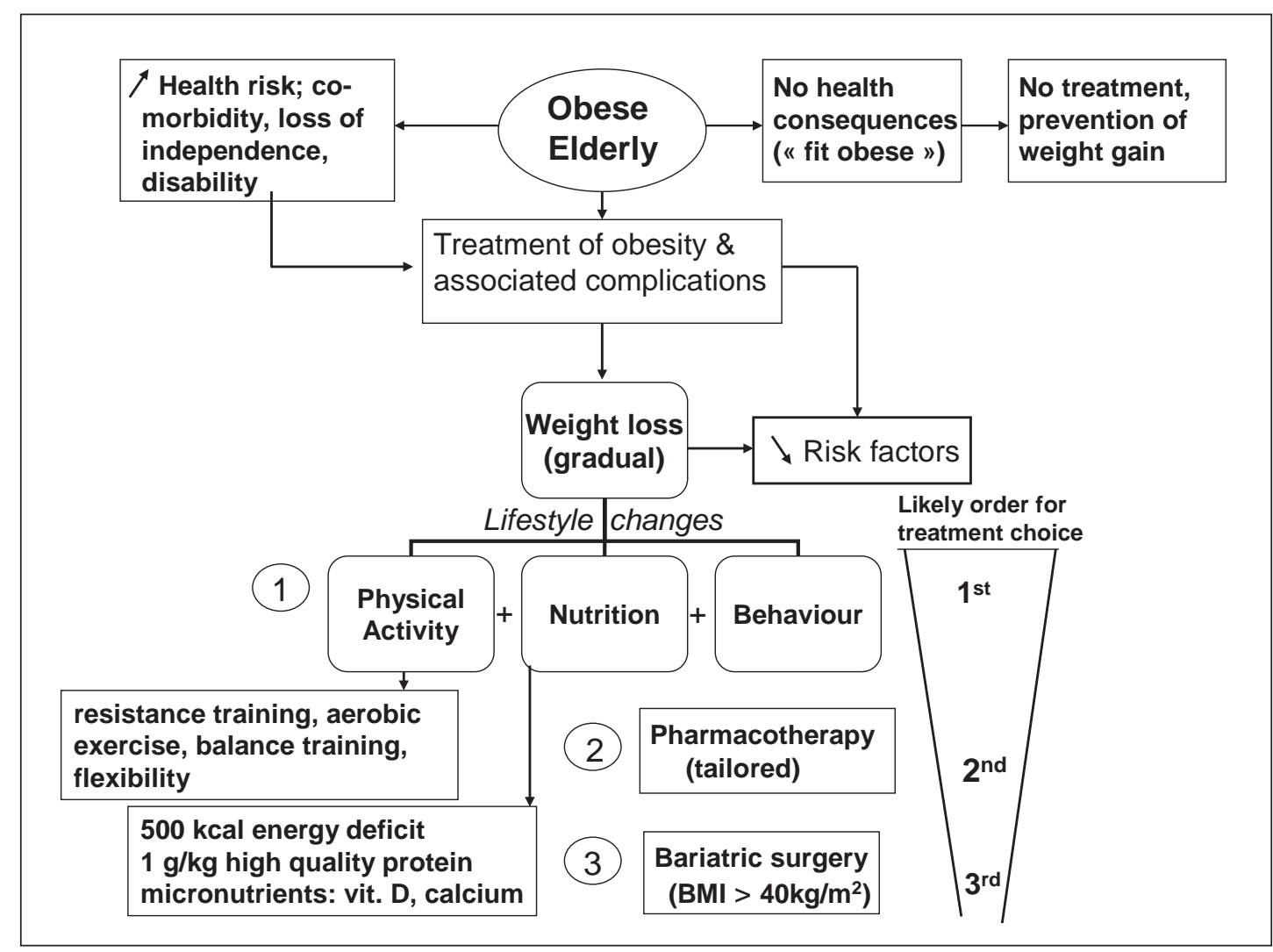

Fig. 2. Simplified schematic treatment strategy for obese elderly individuals.

loneliness, widowhood, dependency from others and institutionalisation may make it difficult to change the life-style $[1,14]$. Chronic disability as well as reduced physical and exercise capacity may interfere with the desired increase in physical activity. Also, older adults frequently face obstacles such as impaired vision and hearing and limited financial resources. In several small clinical trials, the group of Villareal et al. [61] from Washington randomised obese and frail subjects to a control group and a group receiving life-style intervention. Life-style intervention consisted of a $750 \mathrm{kcal}(3.15 \mathrm{MJ})$ deficit energy-restricted diet, behavioural modification and a multi-component exercise programme, 3 times $90 \mathrm{~min}$ per week. These studies were of short (6 months) duration. In subjects with coronary heart disease and metabolic syndrome, the intervention group achieved a greater weight loss and fat mass loss, with significant improvements in all the components of the metabolic syndrome as well as in C-reactive protein (CRP) and IL-6 blood levels. In frail subjects the intervention reversed frailty, increased muscle strength and quality, and improved static and dynamic balance tests [62]. Life-style intervention improved pancreatic $\beta$ cell and $\alpha$ cell function, increased insulin clearance and doubled insulin sensitivity [63]. The only adverse effect consisted of an increased bone turnover and a 2-3\% decrease of hip bone mass [64].

Recently, Villareal et al. [65] reported the results of a larger group of 107 frail obese elderly subjects followed for 1 year. Patients were randomised into a control group, a diet group with a 500-750 kcal (2.1-3.15 MJ) deficit diet with $1 \mathrm{~g}$ protein/kg/day, a multicomponent exercise group and a combined diet plus exercise group. All subjects received a supplement of $1,500 \mathrm{mg}$ calcium and $10 \mu \mathrm{g}$ vitamin D. Compared to the control group, 
the diet group and exercise group reversed their state of frailty, but the combination of diet and exercise was more effective than either individual intervention alone. The combined group achieved the best physical performance, functional status and aerobic endurance capacity. The loss of body weight and fat mass was similar in the diet group and the diet plus exercise group. The quality of life improved, and the only potential adverse effect was a small reduction in lean body mass and bone mineral density in the diet group $(-5 \%$ and $-2.6 \%$, respectively) and in the diet plus exercise group $(-3 \%$ and $-1.1 \%$, respectively).

In the Arthritis, Diet and Activity Promotion Trial (ADAPT), 316 patients older than 60 years of age with osteo-arthritis of the knee were randomised into 4 groups of healthy lifestyle, diet only, multi-component exercise only and a diet plus exercise group [66]. Weight loss was significantly greater in the diet only and the combined diet plus exercise group. Measures of physical function improved but the improvements were the greatest in the diet plus exercise group. Pain scores were 6\% less in the exercise group, 16\% less in the diet group and $30 \%$ less in the diet plus exercise group. These beneficial results became already apparent after 6 months and persisted during the 18 months of the study. Follow-up after 8 years demonstrated no increased mortality [67]. In fact, the groups randomised to diet or diet plus exercise had a 50\% lower mortality than the groups, just receiving advice on healthy life-style or exercise.

- Stepwise treatment options are life-style intervention followed by pharmacotherapy and finally surgery

- Life-style intervention should consist of a $500 \mathrm{kcal}$ (2.1 MJ) deficit diet (range 500-1,000 kcal (2.1-4.2 MJ)) with a sufficient amount of high quality protein $(1.0 \mathrm{~g} / \mathrm{kg})$ and adequate supplementation of calcium (1,000 $\mathrm{mg} /$ day), vitamin D (10-20 $\mu \mathrm{g} /$ day), multivitamins and minerals, combined with exercise and behavioural therapy

- Life-style interventions are feasible, even in frail obese elderly.

\section{Nutrition and Diet}

Diet-induced weight loss results in both a decrease in fat mass and fat-free mass and so could exacerbate the age-related loss of muscle mass and further impair physical function. Based on intensive research concerning sarcopenia (age-related reduction in skeletal muscle mass in the elderly) and sarcopenic obesity, dietary guidelines were adjusted to prevent sarcopenic obesity and to guide the medical profession in managing weight loss in the presence of sarcopenic obesity [13, 14, 19, 20, 68, 69].

In healthy muscle, proteins and amino acids constantly turn over with equilibrium between protein synthesis and protein breakdown. Sarcopenia may be the result of increased rates of protein breakdown secondary to increased cytokine production from adipose tissue and a resulting chronic state of low-grade inflammation. It may also be the consequence of diminished protein synthesis, which is partly due to the anorexia of ageing. Early satiety secondary to a decreased relaxation of the gastric fundus, an increased cholecystokinin release in response to fat intake as well as increased leptin levels and declining testosterone levels in men may account for the anorexia of ageing and result in decreased food and nutrient intake [70-72].

In the treatment of subjects with, or being at risk of, sarcopenic obesity, the energy deficit should be more moderate than usual (range of 200-750 kcal (840-3,150 kJ)) with emphasis on a higher intake of proteins (up to $1.5 \mathrm{~g} / \mathrm{kg}$ ) of high biological quality, ensuring adequate renal function. When restricting the energy intake, protein intake must be maintained or even increased as dietary protein and amino acids are the most effective means to slow down or prevent muscle protein catabolism. In order to optimise the anabolic response 
to ingested high-quality proteins, certain peculiarities of the old age have to be taken into account $[68,69,71,73]$. In contrast to younger people the elderly have a diminished anabolic response to proteins when they are co-ingested with carbohydrates. There is no evidence that co-ingestion of protein and fat affects protein anabolism. So, ageing in itself does not reduce the anabolic response to sufficient amounts of high-quality protein but it is the presence of carbohydrates that blunts this response, explained by the effects of insulin resistance on muscle protein synthesis. Exercise is important, as even a modest bout of physical activity such as 45 min of treadmill walking is sufficient to restore the ability of insulin to stimulate protein synthesis.

Also, protein intake should be strategically timed at each meal to overcome other consequences of ageing such as the blunting of the anabolic response due to changes in digestion, gastric emptying rate, splanchnic uptake and peripheral utilisation. Moreover, in contrast to the young, skeletal muscle in the old requires greater amounts of protein and amino acids to stimulate protein synthesis to a similar extent as that of the young [68]. Protein supplementation increases satiety which is a beneficial side-effect to reduce hunger aiding compliance with an energy-deficient diet. Excessive protein intake should be avoided if renal function is impaired [48].

Another potential strategy to enhance protein synthesis is the supplementation of essential amino acids; mixtures of arginine and glutamine or arginine and lysine have been tried [74, 75]. Also, optimisation of the leucine intake from a minimum requirement of $2 \mathrm{~g}$ /day to an optimum of 6-8 g/day is an option, as leucine increases protein anabolism and decreases protein breakdown $[68,76]$. Leucine-rich foods are legumes (soybeans) and animal products (fish, beef). The addition of leucine to a mixed nutrient meal in older subjects resulted in an increase in muscle protein synthesis of $56 \%$ [77]. Also, supplementation of $\beta$-hydroxy- $\beta$-methylbutyrate (HMB, a leucine metabolite, $2-3 \mathrm{~g}$ daily) resulted in increased total body protein synthesis $[74,75]$.

Specific micronutrients that should be addressed are vitamin $\mathrm{D}$, which is involved in protein synthesis and muscle health $[78,79]$, magnesium - hypomagnesaemia is associated with insulin resistance -, and vitamin $\mathrm{B}_{6}$, vitamin $\mathrm{B}_{12}$ and selenium which are associated with functional decline $[13,14]$. Pharmacological attempts to increase muscle mass by insulin-like growth factor, growth hormone or testosterone posed significant potential side-effects without consistent effects on muscle [80]. Also, the addition of recombinant growth hormone or the synthetic androgen nandrolone to a programme consisting of an energy-restricted diet and exercise did not result in benefits in body composition or muscle performance [81].

In obese older adults with a low muscle mass relative to body weight (relative sarcopenia), a 6-month intervention with a $440 \mathrm{kcal}(1,850 \mathrm{~kJ})$ deficit diet and weekly behavioural therapy without physical exercise resulted in a $10 \%$ body weight loss and a $16.3 \%$ decrease in fat mass and a 5.6\% decrease in fat-free mass [82]. The endurance capacity and exercise tolerance increased as did the cardiovascular and pulmonary efficiency. If these effects can be achieved just by a diet and behavioural therapy, why should one then add exercise to a diet?

- In the presence of, or risk for, sarcopenic obesity a less severe energy restriction (200-500 kcal (820-2,100 kJ) should be coupled to a higher protein intake of high biological quality $(1.5 \mathrm{~g} / \mathrm{kg})$, ensuring adequate renal function

- Proteins should be divided equally over the meals

- Pharmacological therapies to increase muscle mass have no consistent effects on muscle and may have side-effects. 


\section{Why Add Exercise to a Diet?}

Several studies have examined the effects of adding exercise to an energy-restricted diet. While this did not increase weight loss or loss of body fat and visceral fat, there are several reasons to add exercise to a diet.

With added exercise higher basal and stimulated lipolysis was observed in abdominal and gluteal regions and serum levels of CRP and IL-6, indicative of chronic inflammation, decreased [83].

In frail old adults exercise added to the diet reduced the loss of fat-free mass and lean tissue mass and increased muscle strength, suggesting an improved muscle quality by a decreased muscle fat infiltration and a reduced inflammation [84].

The addition of exercise in elderly obese patients with impaired glucose tolerance or type 2 diabetes resulted in an attenuated loss of fat-free mass and muscle mass and prevented the loss of type 1 high-oxidative muscle fibres and type 2 aerobic or glycolytic muscle fibres [85].

In the diet plus exercise group improvements in endurance capacity, muscle strength, plasma triglycerides and LDL-cholesterol, and diastolic blood pressure were seen. The intrahepatic fat content decreased to a similar extent in both groups and was accompanied by a comparable improvement of insulin sensitivity [86].

Finally, a systematic review and meta-analysis of interventions to achieve long-term weight loss in obese older people (age $\geq 60$ years, BMI $>30 \mathrm{~kg} / \mathrm{m}^{2}$, follow-up $>1$ year) reported that combined dietary advice and physical activity achieved the highest weight loss as well as a greater decrease in serum total cholesterol [87]. Weinheimer et al. [88] performed a systematic review of the separate and combined effects of energy restriction and exercise on fat-free mass in middle-aged and older adults concluding the importance of exercise in combating sarcopenic obesity. The addition of exercise to energy restriction clearly attenuated the loss of fat-free mass which went down from 24 to $11 \%$. They confirmed (in the elderly) the findings of a 1995 meta-analysis in young adults where exercise added to energy restriction reduced the loss of fat-free mass from 25 to $12 \%$ [89].

- Adding physical exercise to a diet has important benefits including

- Decreasing the chronic low-grade inflammatory state

- Decreasing the fat-free mass loss

- Increasing muscle quality and quantity

- Increasing functional capabilities

- Increasing insulin sensitivity.

\section{Physical Exercise}

The American College of Sports Medicine recommends a multi-component training exercise programme (strength, endurance, balance, flexibility) to improve and maintain physical function in older adults [90]. Resistance training has been investigated as an approach to counteract sarcopenia in older adults by stimulating protein synthesis and causing muscle hypertrophy with increased muscle mass and muscle strength and with improved physical functioning and performance of simple and complex activities in older people [91]. Endurance training improves aerobic capacity. Most of the studies had a multicomponent programme of 3 times/week 90 min sessions, consisting of 15 min of balance training, $15 \mathrm{~min}$ of flexibility, $30 \mathrm{~min}$ of aerobic exercise and $30 \mathrm{~min}$ of high-intensity resistance training.

To study the impact of each exercise modality in more detail, Davidson et al. [92] randomised 136 60- to 80-year-old obese subjects into 4 groups: a control group, a group that had progressive resistance training, a group that performed aerobic exercise and a 
group that combined progressive resistance training with aerobic exercise. After 6 months, body weight decreased by $0.6 \mathrm{~kg}$ in the resistance, by $2.8 \mathrm{~kg}$ in the aerobic and by $2.3 \mathrm{~kg}$ in the combined exercise group. Abdominal fat and visceral fat decreased and endurance capacity improved significantly in the aerobic and combined exercise group. Skeletal mass and muscle strength increased in the resistance and combined exercise groups only. Insulin resistance improved by $31 \%$ in the aerobic group and by $45 \%$ in the combined exercise group, whereas it did not change in the resistance training group. The fear of a negative interference of endurance and resistance training was not substantiated [93, 94]. Thus, the combination of progressive resistance training and aerobic exercise is the optimal exercise strategy for simultaneous improvement of insulin resistance and functional limitations in the elderly. Aerobic exercise only is a second best choice.

The importance of exercise was investigated in 2 studies. Frail old subjects, randomised to a diet or to exercise, showed a weight loss of $7.1 \%$ after 12 weeks in the diet group and no weight loss in the exercise group [95]. Fat-free mass decreased by $4.8 \%$ as a result of weight loss and increased by $2.7 \%$ as a result of exercise. Exercise resulted in a significant decrease in cytokine expression (TNF- $\alpha$, IL-6) in skeletal muscle and a significant increase of muscle growth factors and anabolism. Similarly, in the 65- to 80-year-old, moderately frail, obese adults exercise had no effect on body weight but caused major changes in body composition such as decreased fat mass and increased fat-free mass [96]. Endurance, muscle strength and functional mobility increased significantly. Adding multi-component exercise resulted in a $50 \%$ higher basal and post-meal protein synthesis rate.

Three meta-analyses examined the effects of physical activity on health-related quality of life in older adults [97-99]. None of these meta-analyses performed a separate subanalysis with respect to the presence of normal weight, overweight or obesity.

Schechtman and Ory [97] examined the Frailty and Injuries: Cooperative Studies of Interventional Techniques (FICSIT), a linked series of randomised trials focussed on the benefits of exercise in the frail elderly. Of the SF-36 scales, an improved emotional health with a trend toward improved social functioning was associated with physical activity. In another meta-analysis of 36 studies in old subjects without clinical disorders [98], 4 components of quality of life were examined. Psychological well-being was significantly improved. Self-efficacy, overall well-being and view-of-self tended to be improved in physically active subjects. The third meta-analysis of 11 studies in community-dwelling older adults with SF-36 scales demonstrated an improvement in the self-reported physical function [99].

- Physical exercise should consist of a multi-component programme of 3 times/week 90-min sessions, consisting of 15 min of balance training, 15 min of flexibility, 30 min of aerobic exercise and 30 min of high-intensity resistance training

- The combination of progressive resistance training and aerobic exercise is the optimal exercise strategy for simultaneous improvement of insulin resistance and functional limitations in the elderly. Aerobic exercise only is a second best choice.

- Physical exercise also improves quality of life.

Why Add a Diet to Exercise?

Despite beneficial effects on body composition and insulin resistance, only small amounts of weight loss can be obtained by exercise only. Is there additional benefit from adding a diet to exercise interventions?

In older obese adults with metabolic syndrome similar improvements of all components of the metabolic syndrome occurred in the exercise and exercise plus diet group in the short term of 12 weeks, but the combination resulted in greater weight loss and subcutaneous fat mass loss [100]. In a large study 288 older, obese adults with poor cardiovascular health 
were randomised to a successful ageing control arm, a physical activity and an energyrestricted diet arm and physical activity arm for 18 months [101]. In the combined diet and physical activity group subjects lost more weight, were better able to maintain the lost weight and had the best physical performance tests.

- Diet should be added to physical exercise because of

- A greater weight loss and fat loss

- A better maintenance of weight loss and

- A better physical performance.

\section{Barriers and Perceived Constraints to Participate in Physical Exercise}

The Screening and Counselling for Physical Activity and Mobility in Older People (SCAMOP) study examined 619 subjects 75-83 years of age and with a BMI between 20 and $53 \mathrm{~kg} / \mathrm{m}^{2}$ [102]. The objective was to examine what they felt were constraints to exercise and whether these perceived constraints explained physical inactivity. Compared to the non-obese elderly (BMI $20-29.9 \mathrm{~kg} / \mathrm{m}^{2}$ ), the moderately obese (BMI $30-34.9 \mathrm{~kg} / \mathrm{m}^{2}$ ) had twice the risk of inactivity and the severely obese (BMI $\geq 35 \mathrm{~kg} / \mathrm{m}^{2}$ ) 4 times the risk of inactivity. Poor health, pain, diseases and tiredness explained $27 \%$ of the increased risk of physical inactivity. Fear and negative experiences, such as the fear of falling, the fear of injury, exercise experienced as uncomfortable and insecurity when exercising outdoors, contributed $23 \%$ to the increased risk of inactivity. All these factors entered in the model together with the item of having no interest in exercise explained $42 \%$ of the increased risk of physical inactivity. These factors were substantially more frequent among the severely obese.

A meta-analysis of 43 studies in 33,090 60- to 70-year-olds rejected the hypothesis that interventions to increase physical activity failed to be effective in older adults [103]. Several modulating factors were found that can be used to increase the physical activity amongst elders. One should only target physical activity and not couple this to health education. Also, one should focus on group activity, encourage moderate exercise intensity and activity, incorporate self-monitoring, and encourage centre-based activities with an intense contact with the interventionists at a structured time.

- Physical activity is feasible in the elderly

- Factors shown to constrain exercise and to modulate activity should be taken into account when setting up physical activity programmes (e.g. being a social activity as a group in a centre guided by a private coach).

\section{Pharmacotherapy}

Older subjects have been excluded from most clinical trials of pharmacological agents for weight loss. The average age of subjects ranged from 34 to 54 years in a meta-analysis of pharmacotherapy [104]. Of the many drugs that were developed to treat obesity, most have been withdrawn from the market, and in Europe, only orlistat is currently approved for a long-term treatment in patients with a BMI $\geq 30 \mathrm{~kg} / \mathrm{m}^{2}$ and in patients with a BMI of 27-29.9 $\mathrm{kg} / \mathrm{m}^{2}$ in the presence of obesity-related co-morbidities $[105,106]$.

Orlistat, a lipase inhibitor, blocks the digestion and absorption of up to one third of the ingested fat amount, causing an energy deficit of approximately $300 \mathrm{kcal} /$ day $(1,260 \mathrm{~kJ})$. Adding orlistat to diet and life-style results in 2-3 kg additional weight loss compared to adding placebo and in improved glucose tolerance and blood pressure dependent on the rate 
of weight loss $[104,107,108]$. However, a weight loss-independent beneficial effect on dyslipidaemia and insulin resistance have been demonstrated $[109,110]$.

Gastrointestinal side-effects result from orlistat's mode of action and consist of flatulence, faecal incontinence, oily spotting, urge, steatorrhoea and abdominal cramps but are only likely to occur if high-fat meals ( $>20 \mathrm{~g}$ fat/meal) are consumed. The absorption of fatsoluble vitamins (A, D, E and $\mathrm{K}$ ) is reduced by orlistat, but while they do not fall into the deficiency range, it has been suggested that vitamin supplementation should be given to those on orlistat for an extended period of time. When fat-soluble vitamins are supplied such as vitamin $\mathrm{D}$, they should be ingested $2 \mathrm{~h}$ prior to the ingestion of orlistat. While more liquid stools may help the many constipated elders, they can cause faecal incontinence particularly as the elderly are more likely to have impaired internal and external sphincter function. The analysis of an older subpopulation of a 2-year randomised study in the primary care setting found that orlistat was just as effective in adults aged 65 years and older as in younger adults $[111,112]$. Also, the gastrointestinal side-effects were not different in older than in younger subjects [112].

Older people often take large numbers of drugs, some of which may be associated with weight gain and are best avoided or substituted for those that are weight neutral. The drugs that may cause weight gain with their alternatives are mentioned in table 2 . Specifically in the management of diabetes, sulfonylureas, meglitines, thiazolidinediones and insulin induce weight gain, while acarbose ( $\alpha$-glucosidase inhibitor), metformin and gliptins (dipeptidyl peptidase-4 (DPP-4) inhibitors) are weight neutral (table 3) [113, 114]. Glucagon-like peptide-1 (GLP-1) receptor agonists decrease body weight by $2.9 \%$ (95\% confidence interval 2.2-3.63) in a meta-analysis of 25 studies. In patients without diabetes ( 3 trials) weight losses were $3.2(2.1-4.3) \mathrm{kg}$ and in patients with diabetes 2.8 (2.3-3.4) $\mathrm{kg}$ [115]. As is the case for orlistat, no data are available for the elderly.

- Orlistat, a lipase inhibitor, is the only currently licensed anti-obesity drug recommended for use, but outcome data in the elderly are lacking

- Many drugs used to treat diabetes cause weight gain, weight neutral alternatives are acarbose, metformin and DPP-4 inhibitors; weight reduction is achieved by GLP-1 receptor agonists

- Identifying, and finding alternatives to, drugs that can cause weight gain in the elderly is important.

\section{Bariatric Surgery}

Bariatric surgery is indicated for subjects with severe obesity, and most guidelines suggest these include patients with a BMI $\geq 40 \mathrm{~kg} / \mathrm{m}^{2}$ or a BMI $\geq 35 \mathrm{~kg} / \mathrm{m}^{2}$ with co-morbidity such as cardiorespiratory disease, diabetes, sleep apnoea and severe osteoarthritis, which are expected to improve by surgically induced weight loss. A more recent position statement from the International Federation of Diabetes suggests that a lower BMI threshold ( $>30 \mathrm{~kg} / \mathrm{m}^{2}$ ) should be set for those with type 2 diabetes.

A number of case-controlled and cohort studies as well as a small number of randomised trials have shown that bariatric surgery reduces mortality (from cancer in women, cardiovascular disease and diabetes) and improves quality of life [116, 117]. Several different types of procedures are performed (Roux-en-Y gastric bypass, sleeve gastrectomy, adjustable gastric banding as well as biliopancreatic diversion with or without duodenal switch) but there are few data to guide selection of procedure for any individual, least of all in the elderly.

Age limitations between 18 and 50 years by the NIH Consensus Conferences in 1991 were widened over time to the age of 60 years $[46,118,119]$. With the improvement in 
Table 2. Medication resulting in weight gain and their potential alternatives

\begin{tabular}{lll}
\hline Medication group & Medication causing weight gain & Alternative medication \\
\hline Treatment for diabetes & $\begin{array}{l}\text { sulfonylureas } \\
\text { thiazolidinediones } \\
\text { meglitines } \\
\text { insulin }\end{array}$ & $\begin{array}{l}\alpha \text {-glucosidase inhibitor } \\
\text { metformin } \\
\text { DDP-4 inhibitors } \\
\text { GLP-1 receptor agonists }\end{array}$ \\
\hline Antidepressants & $\begin{array}{ll}\text { tricyclic antidepressants } \\
\text { mono-amine oxidase inhibitors } \\
\text { selective serotonine reuptake inhibitors } \\
\text { (paroxetine) }\end{array}$ & $\begin{array}{l}\text { fluoxetine } \\
\text { sertraline }\end{array}$ \\
\hline Antipsychotics & $\begin{array}{l}\text { clozapine } \\
\text { risperidon } \\
\text { olanzapine }\end{array}$ & no alternatives \\
\hline Anticonvulsants & valproic acid & topiramate \\
\hline Antihypertensive drugs & carbamazepine & ACE inhibitors \\
\hline
\end{tabular}

Table 3. Treatment for type 2 diabetes: mechanism of action and effects on glucose metabolism and body weight [113-115]

$\Delta$ glucose, mmol/l $\quad \Delta$ HbA1c, $\% \quad \Delta$ body weight Mechanism of action

\section{Oral}

$\alpha$-glucosidase inhibitor

Metformin

$\approx 0.5$

$\approx 1-4$

$\approx 0.5-1.0$

$\approx 1-2$

$-$

$\downarrow /-$

Sulphonyl ureas

$\approx 2-4$

$\approx 1-2$

$\uparrow$

Meglitines

$\approx 1-3$

Gliptines (DDP-4 inhibitors)

$\approx 0.6-1.2$

$\approx 0.5-1.5$

$\uparrow /-$

Thiazolidinediones

$\approx 2-3$

$\approx 0.6-1.5$

$\approx 0.6-2.0$ slowing of carbohydrate digestion reduction of insulin resistance and hepatic glucose output, increased glucose utilisation

increased insulin secretion, binding to SUR1 receptor on $\beta$-cells increased insulin secretion, binding to SUR1 receptor, rapid onset, short duration increased insulin secretion, prevention of degradation of incretins increased insulin action and adipogenesis, stimulation of PPAR- $\gamma$, altered glucosefatty acid cycle

\section{Injection}

GLP-1 receptor agonists $\quad \approx 0.7--2.0 \quad \approx 0.5-2.0 \quad \downarrow$

Insulins

$\begin{array}{ll}\begin{array}{ll}\text { adjust dose and } \\ \text { regimen as needed }\end{array} & \begin{array}{l}\text { adjust dose } \\ \text { and regimen } \\ \text { as needed }\end{array}\end{array}$

increased insulin secretion and decreased glucagon secretion, resistance to DDP-4 degradation, potentiation of prandial insulin secretion decreased lipolysis and hepatic glucose output, increased peripheral glucose uptake, storage and utilisation 
intra-operative surgical management and optimisation of peri-operative care, many centres offer bariatric surgery to patients who exceed this age limit. Retrospective data of operations, mainly performed by laparoscopy in the last decade, are shown in table 4 [120126]. Older obese adults suffered from more co-morbidities and required more medications prior to surgery than younger obese subjects. After bariatric surgery the elderly lost clinically significant amounts of weight, and this weight loss was associated with an improvement in obesity-related co-morbidities and an overall reduction in medication requirements. Compared to older patients, younger adults lost more weight and had a higher level of resolution of obesity-associated diseases. Overall mortality after bariatric surgery is low and of an acceptable risk:benefit ratio [125]. Complication rates are also low and related to underlying diseases, and not to the operative technique or procedure itself. None of the mentioned studies provided data on the number of subjects in whom the surgeons declined to perform the operation because of major life-limiting processes or unacceptable cardiorespiratory risk factors or because surgical risks outweighed the expected benefits. Most of the enrolled subjects were females, and, according to a very recent study in veterans, sex differences should be taken into account [127]. No benefit in survival during a mean of 6.7 years of follow-up was observed in obese older males with obesity-related co-morbidities, which could partly be explained by the shortness of followup but which might also be related to the fact that bariatric surgery appeared to be more difficult in severely obese male patients.

- Bariatric surgery can be safely performed and be clinically effective in the elderly

- The eldery lose clinically significant amounts of weight, associated with an improvement in obesity-related co-morbidities and an overall reduction in medication requirements

- Data are not available to determine the optimal procedure(s) in the elderly in general or for any individual

- The elderly should not be denied bariatric surgery solely on age grounds.

\section{Conclusion}

Obesity is a major public health problem. The population is growing older and the prevalence of obesity in the elderly is rising. Ageing and obesity are two conditions that represent an important part of health-care costs. An increasing obese elderly population will undoubtedly pose growing financial problems to the health-care system. Although not much is to be gained in life expectancy in the old age, obesity-related co-morbidities and, in particular, obesity-related disabilities are of major concern as they may interfere with independency and activities of daily living and with quality of life. Increased health-care and societal costs of treatment are justified by a lesser need for medication, a lower need of nursing home admission and a better quality of the remaining life.

Although cut-off values of BMI, waist circumference and percentages of fat mass have not been defined for the elderly, it is clear from several meta-analyses that mortality and morbidity associated with overweight and obesity only increase at a BMI above $30 \mathrm{~kg} / \mathrm{m}^{2}$ in the elderly. Thus, treatment should only be offered to patients who are obese rather than overweight (by BMI definition) and who have functional impairments, metabolic complications or obesity-related diseases that can benefit from weight loss. The weight loss therapy should minimise muscle and bone loss and vigilance as to the development of sarcopenic obesity should always be present.

Life-style intervention should be the first step, and its effects are well studied in the obese elderly. This should consist of a balanced diet with a $500 \mathrm{kcal}(2.1 \mathrm{MJ})$ energy deficit 

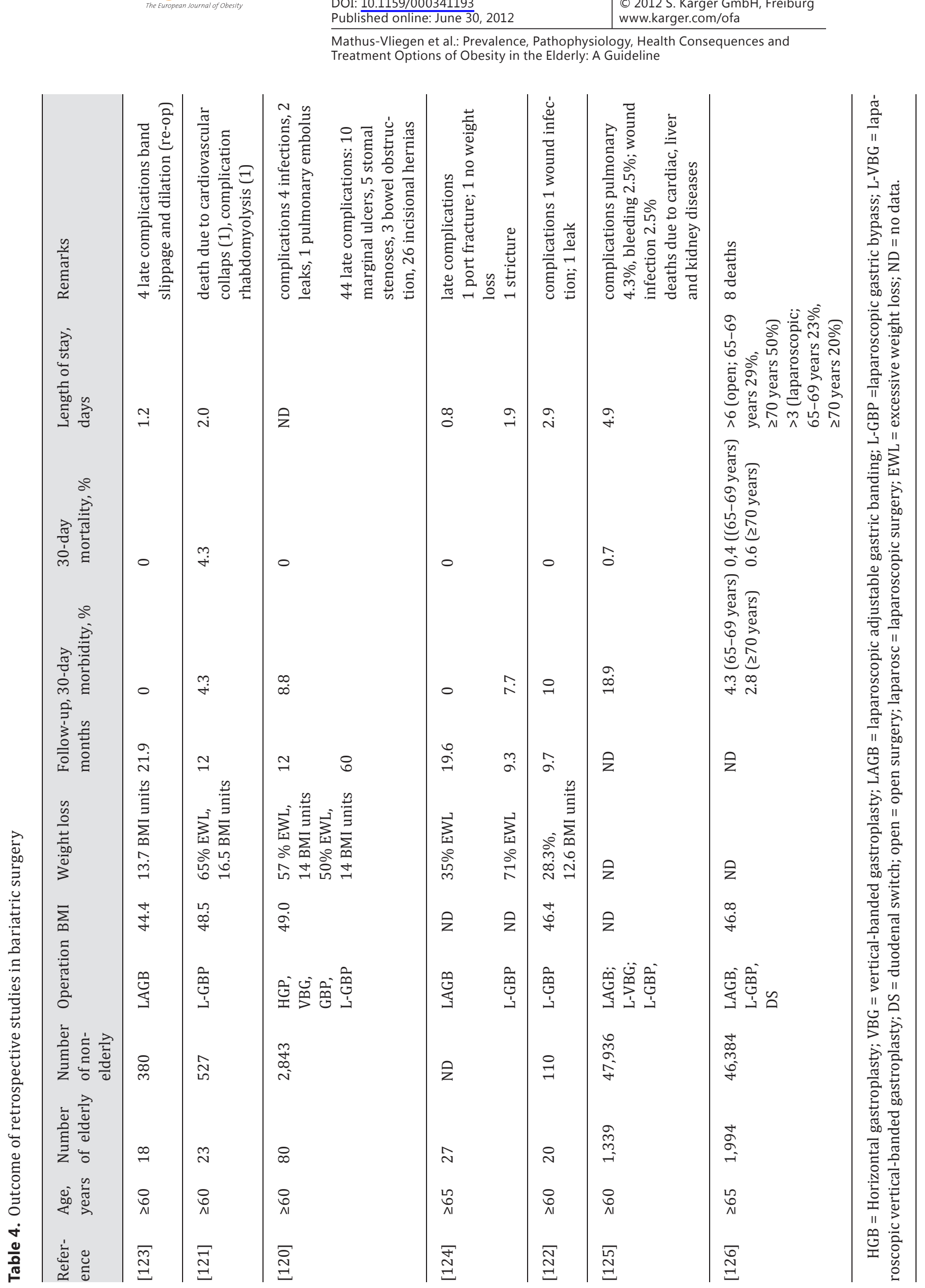
and an adequate intake of protein of high biological quality together with calcium and vitamin D, behavioural therapy and multi-component exercise. Multi-component exercise includes flexibility training, balance training, aerobic exercise and resistance training. The adherence rate in most studies is around $75 \%$. Knowledge of constraints and modulators of physical inactivity should be of help to engage the elderly in physical activity. The role of pharmacotherapy and bariatric surgery in the elderly is largely unknown as in most studies people aged 65 years and older have been excluded.

Research on the definition of obesity in the elderly, on clinical tools to evaluate sarcopenia, on the optimal diet and the pharmacology of drugs in the obese elderly, as well as cost-benefit studies on the management of obesity in the elderly should be encouraged.

\section{References}

1 Han TS, Tajar A, Lean ME: Obesity and weight management in the elderly. Br Med Bull 2011;97:169-196.

2 Population Projections 2008-2060-. http://europa.eu/rapid/pressReleasesAction.do? reference=STAT/08/119 (accessed May 3, 2012).

- 3 Rossner S: Obesity in the elderly - -a future matter of concern? Obes Rev 2001;2:183-188.

- 4 Diouf I, Charles MA, Ducimetiere P, Basdevant A, Eschwege E, Heude B: Evolution of obesity prevalence in France: an age-period-cohort analysis. Epidemiology 2010;21:360-365.

- 5 Gutierrez-Fisac JL, Guallar-Castillon P, Leon-Munoz LM, Graciani A, Banegas JR, Rodriguez-Artalejo F: Prevalence of general and abdominal obesity in the adult population of Spain, 2008-2010: the ENRICA study. Obes Rev 2012;13:388-392.

6 Measuring the Netherlands: A monitoring study of risk factors in the general population 2009-2010. Bilthoven, RIVM, 2011; Report No.: 260152001/2011.

- 7 Ruesten A, Steffen A, Floegel A, Van der A DL, Masala G, Tjonneland A, et al: Trend in obesity prevalence in European adult cohort populations during follow-up since 1996 and their predictions to 2015. PLoS One 2011;6:e27455.

- 8 Arterburn DE, Crane PK, Sullivan SD: The coming epidemic of obesity in elderly Americans. J Am Geriatr Soc 2004;52:1907-1912.

- 9 Li F, Fisher KJ, Harmer P: Prevalence of overweight and obesity in older U.S. adults: estimates from the 2003 Behavioral Risk Factor Surveillance System survey. J Am Geriatr Soc 2005;53:737-739.

10 Leveille SG, Wee CC, Iezzoni LI: Trends in obesity and arthritis among baby boomers and their predecessors, 1971-2002. Am J Public Health 2005;95:1607-1613.

11 Kennedy RL, Chokkalingham K, Srinivasan R: Obesity in the elderly: who should we be treating, and why, and how? Curr Opin Clin Nutr Metab Care 2004;7:3-9.

-12 Zamboni M, Mazzali G, Zoico E, Harris TB, Meigs JB, Di Franchesco V, et al: Health consequences of obesity in the elderly: a review of four unresolved questions. Int J Obes (Lond) 2005;29:1011-1029.

13 Villareal DT, Apovian CM, Kushner RF, Klein S: Obesity in older adults: technical review and position statement of the American Society for Nutrition and NAASO, The Obesity Society. Obes Res 2005;13:18491863.

14 Villareal DT, Apovian CM, Kushner RF, Klein S: Obesity in older adults: technical review and position statement of the American Society for Nutrition and NAASO, The Obesity Society. Am J Clin Nutr 2005;82: 923-934.

15 Lim EL, Hollingsworth KG, Aribisala BS, Chen MJ, Mathers JC, Taylor R: Reversal of type 2 diabetes: normalisation of beta cell function in association with decreased pancreas and liver triacylglycerol. Diabetologia 2011;54:2506-2514.

16 Chau D, Cho LM, Jani P, St Jeor ST: Individualizing recommendations for weight management in the elderly. Curr Opin Clin Nutr Metab Care 2008;11:27-31.

-17 Schrager MA, Metter EJ, Simonsick E, Ble A, Bandinelli S, Lauretani F, et al: Sarcopenic obesity and inflammation in the InCHIANTI study. J Appl Physiol 2007;102:919-925.

-18 Florez H, Troen BR: Fat and inflammaging: a dual path to unfitness in elderly people? J Am Geriatr Soc 2008; 56:558-560.

19 Zamboni M, Mazzali G, Fantin F, Rossi A, Di Franchesco V: Sarcopenic obesity: a new category of obesity in the elderly. Nutr Metab Cardiovasc Dis 2008;18:388-395.

-20 Waters DL, Baumgartner RN, Garry PJ, Vellas B: Advantages of dietary, exercise-related, and therapeutic interventions to prevent and treat sarcopenia in adult patients: an update. Clin Interv Aging 2010;5:259270.

21 Kennedy RL, Malabu U, Kazi M, Shahsidhar V: Management of obesity in the elderly: too much and too late? J Nutr Health Aging 2008;12:608-621. 
National Institutes of Health, National Heart, Lung and Blood Institute: Clinical Guidelines on the identification, evaluation, and treatment of overweight and obesity in adults - the evidence report. Obes Res 1998; 6(suppl 2):1S-209S.

23 Heiat A, Vaccarino V, Krumholz HM: An evidence-based assessment of federal guidelines for overweight and obesity as they apply to elderly persons. Arch Intern Med 2001;161:1194-1203. Janssen I, Mark AE: Elevated body mass index and mortality risk in the elderly. Obes Rev 2007;8:41-59. (A) Llewellyn DJ, Alexander

Geriatr Soc 2008;56:1474-1478.

Kuk JL, Ardern CI: Influence of age on the association between various measures of obesity and all-cause mortality. J Am Geriatr Soc 2009;57:2077-2084.

-27 Stessman J, Jacobs JM, Ein-Mor E, Bursztyn M: Normal body mass index rather than obesity predicts greater mortality in elderly people: the Jerusalem longitudinal study. J Am Geriatr Soc 2009;57:2232-2238.

28 McAuley P, Pittsley J, Myers J, Abella J, Froelicher VF: Fitness and fatness as mortality predictors in healthy older men: the veterans exercise testing study. J Gerontol A Biol Sci Med Sci 2009;64:695-699.

-29 McAuley PA, Kokkinos PF, Oliveira RB, Emerson BT, Myers JN: Obesity paradox and cardiorespiratory fitness in 12,417 male veterans aged 40 to 70 years. Mayo Clin Proc 2010;85:115-121

30 Oreopoulos A, Kalantar-Zadeh K, Sharma AM, Fonarow GC: The obesity paradox in the elderly: potential mechanisms and clinical implications. Clin Geriatr Med 2009;25:643-659, viii.

31 Chapman IM: Obesity paradox during aging. Interdiscip Top Gerontol 2010;37:20-36

32 Osher E, Stern N: Obesity in elderly subjects: in sheep's clothing perhaps, but still a wolf! Diabetes Care 2009;32(suppl 2):S398-S402.

Ades PA, Savage PD: The obesity paradox: perception vs knowledge. Mayo Clin Proc 2010;85:112-114.

Goodpaster BH, Krishnaswami S, Harris TB, Katsiaras A, Kritchevsky SB, Simonsick EM, et al: Obesity, regional body fat distribution, and the metabolic syndrome in older men and women. Arch Intern Med 2005;165:777-783.

35 Bokura H, Yamaguchi S, Iijima K, Nagai A, Oguro H: Metabolic syndrome is associated with silent ischemic brain lesions. Stroke 2008;39:1607-1609.

-36 Beydoun MA, Beydoun HA, Wang Y: Obesity and central obesity as risk factors for incident dementia and its subtypes: a systematic review and meta-analysis. Obes Rev 2008;9:204-218.

37 Xu WL, Atti AR, Gatz M, Pedersen NL, Johansson B, Fratiglioni L: Midlife overweight and obesity increase late-life dementia risk: a population-based twin study. Neurology 2011;76:1568-1574.

-38 Bui AL, Horwich TB, Fonarow GC: Epidemiology and risk profile of heart failure. Nat Rev Cardiol 2011;8: $30-41$.

-39 Nicklas BJ, Cesari M, Penninx BW, Kritchevsky SB, Ding J, Newman A, et al: Abdominal obesity is an independent risk factor for chronic heart failure in older people. J Am Geriatr Soc 2006;54:413-420.

40 Harrington J, Lee-Chiong T: Obesity and aging. Clin Chest Med 2009;30:609-614, x.

-41 McTigue KM, Hess R, Ziouras J: Obesity in older adults: a systematic review of the evidence for diagnosis and treatment. Obesity (Silver Spring) 2006;14:1485-1497.

42 Rossi A, Fantin F, Di Franchesco V, Guariento S, Giuliano K, Fontana G, et al: Body composition and pulmonary function in the elderly: a 7-year longitudinal study. Int J Obes (Lond) 2008;32:1423-1430.

43 McCarthy LH, Bigal ME, Katz M, Derby C, Lipton RB: Chronic pain and obesity in elderly people: results from the Einstein aging study. J Am Geriatr Soc 2009;57:115-119.

44 Jensen GL, Friedmann JM: Obesity is associated with functional decline in community-dwelling rural older persons. J Am Geriatr Soc 2002;50:918-923.

45 Bouchard DR, Pickett W, Janssen I: Association between obesity and unintentional injury in older adults Obes Facts 2010;3:363-369.

-46 Blaum CS, Xue QL, Michelon E, Semba RD, Fried LP: The association between obesity and the frailty syndrome in older women: the Women's Health and Aging Studies. J Am Geriatr Soc 2005;53:927-934.

47 Caterson ID, Finer N, Coutinho W, Van Gaal LF, Maggioni AP, Torp-Pedersen C, et al: Maintained intentional weight loss reduces cardiovascular outcomes: results from the Sibutramine Cardiovascular OUTcomes (SCOUT) trial. Diabetes Obes Metab 2011; doi: 10.1111/j.1463-1326.2011.01554.x.

48 Kyrou I, Tsigos C: Obesity in the elderly diabetic patient: is weight loss beneficial? No. Diabetes Care 2009 32(suppl 2):S403-S409.

49 Ensrud KE, Cauley J, Lipschutz R, Cummings SR: Weight change and fractures in older women. Study of Osteoporotic Fractures Research Group. Arch Intern Med 1997;157:857-863.

$\checkmark 50$ Schott AM, Cormier C, Hans D, Favier F, Hausherr E, Dargent-Molina P, et al: How hip and whole-body bone mineral density predict hip fracture in elderly women: the EPIDOS Prospective Study. Osteoporos Int 1998; 8:247-254.

51 Dengel DR, Hagberg JM, Coon PJ, Drinkwater DT, Goldberg AP: Effects of weight loss by diet alone or combined with aerobic exercise on body composition in older obese men. Metabolism 1994;43:867-871.

-52 Gallagher D, Kovera AJ, Clay-Williams G, Agin D, Leone P, Albu J, et al: Weight loss in postmenopausal obesity: no adverse alterations in body composition and protein metabolism. Am J Physiol Endocrinol Metab 2000;279:E124-E131.

53 Roubenoff R: Sarcopenic obesity: the confluence of two epidemics. Obes Res 2004;12:887-888.

54 Miller SL, Wolfe RR: The danger of weight loss in the elderly. J Nutr Health Aging 2008;12:487-491. 
-55 Baumgartner RN, Wayne SJ, Waters DL, Janssen I, Gallagher D, Morley JE: Sarcopenic obesity predicts instrumental activities of daily living disability in the elderly. Obes Res 2004;12:1995-2004.

56 Bouchard DR, Dionne IJ, Brochu M: Sarcopenic/obesity and physical capacity in older men and women: data from the Nutrition as a Determinant of Successful Aging (NuAge) - the Quebec Longitudinal Study. Obesity (Silver Spring) 2009;17:2082-2088.

57 Stenholm S, Rantanen T, Heliovaara M, Koskinen S: The mediating role of C-reactive protein and handgrip strength between obesity and walking limitation. J Am Geriatr Soc 2008;56:462-469.

58 Stenholm S, Harris TB, Rantanen T, Visser M, Kritchevsky SB, Ferrucci L: Sarcopenic obesity: definition, cause and consequences. Curr Opin Clin Nutr Metab Care 2008;11:693-700.

-59 Diabetes Prevention Program Research Group, Crandall J, Schade D, Ma Y, Fujimoto WY, Barrett-Connor E, et al: The influence of age on the effects of lifestyle modification and metformin in prevention of diabetes. J Gerontol A Biol Sci Med Sci 2006;61:1075-1081.

60 Bales CW, Buhr G: Is obesity bad for older persons? A systematic review of the pros and cons of weight reduction in later life. J Am Med Dir Assoc 2008;9:302-312.

-61 Villareal DT, Miller BV III, Banks M, Fontana L, Sinacore DR, Klein S: Effect of lifestyle intervention on metabolic coronary heart disease risk factors in obese older adults. Am J Clin Nutr 2006;84:1317-1323.

-62 Villareal DT, Banks M, Sinacore DR, Siener C, Klein S: Effect of weight loss and exercise on frailty in obese older adults. Arch Intern Med 2006;166:860-866.

-63 Villareal DT, Banks MR, Patterson BW, Polonsky KS, Klein S: Weight loss therapy improves pancreatic endocrine function in obese older adults. Obesity (Silver Spring) 2008;16:1349-1354.

64 Villareal DT, Shah K, Banks MR, Sinacore DR, Klein S: Effect of weight loss and exercise therapy on bone metabolism and mass in obese older adults: a one-year randomized controlled trial. J Clin Endocrinol Metab 2008;93:2181-2187.

65 Villareal DT, Chode S, Parimi N, Sinacore DR, Hilton T, Armamento-Villareal R, et al: Weight loss, exercise, or both and physical function in obese older adults. N Engl J Med 2011;364:1218-1229.

66 Messier SP, Loeser RF, Miller GD, Morgan TM, Rejeski WJ, Sevick MA, et al: Exercise and dietary weight loss in overweight and obese older adults with knee osteoarthritis: the Arthritis, Diet, and Activity Promotion Trial. Arthritis Rheum 2004;50:1501-1510.

67 Shea MK, Houston DK, Nicklas BJ, Messier SP, Davis CC, Miller ME, et al: The effect of randomization to weight loss on total mortality in older overweight and obese adults: the ADAPT Study. J Gerontol A Biol Sci Med Sci 2010;65:519-525.

-68 Paddon-Jones D, Rasmussen BB: Dietary protein recommendations and the prevention of sarcopenia. Curr Opin Clin Nutr Metab Care 2009;12:86-90.

69 Morley JE, Argiles JM, Evans WJ, Bhasin S, Cella D, Deutz NE, et al: Nutritional recommendations for the management of sarcopenia. J Am Med Dir Assoc 2010;11:391-396.

70 Altman DF: Changes in gastrointestinal, pancreatic, biliary, and hepatic function with aging. Gastroenterol Clin North Am 1990;19:227-234. Lovat LB: Age related changes in gut physiology and nutritional status. Gut 1996;38:306-309. MacIntosh C, Morley JE, Chapman IM: The anorexia of aging. Nutrition 2000;16:983-995.

73 Breen L, Phillips SM: Skeletal muscle protein metabolism in the elderly: Interventions to counteract the 'anabolic resistance' of ageing. Nutr Metab (Lond) 2011;8:68-79.

74 Vukovich MD, Stubbs NB, Bohlken RM: Body composition in 70-year-old adults responds to dietary betahydroxy-beta-methylbutyrate similarly to that of young adults. J Nutr 2001;131:2049-2052.

75 Flakoll P, Sharp R, Baier S, Levenhagen D, Carr C, Nissen S: Effect of beta-hydroxy-beta-methylbutyrate, arginine, and lysine supplementation on strength, functionality, body composition, and protein metabolism in elderly women. Nutrition 2004;20:445-451.

76 Layman DK, Walker DA: Potential importance of leucine in treatment of obesity and the metabolic syndrome. J Nutr 2006;136(1 suppl):319S-323S.

-77 Rieu I, Balage M, Sornet C, Giraudet C, Pujos E, Grizard J, et al: Leucine supplementation improves muscle protein synthesis in elderly men independently of hyperaminoacidaemia. J Physiol 2006;575:305-315.

78 Bischoff-Ferrari HA: Relevance of vitamin D in muscle health. Rev Endocr Metab Disord 2012;13:71-77.

79 Dawson-Hughes B: Serum 25-hydroxyvitamin D and muscle atrophy in the elderly. Proc Nutr Soc 2012;71: 46-49.

80 Janssens H, Vanderschueren DM: Endocrinological aspects of aging in men: is hormone replacement of benefit? Eur J Obstet Gynecol Reprod Biol 2000;92:7-12.

81 Sartorio A, Maffiuletti NA, Agosti F, Marinone PG, Ottolini S, Lafortuna CL: Body mass reduction markedly improves muscle performance and body composition in obese females aged 61-75 years: comparison between the effects exerted by energy-restricted diet plus moderate aerobic-strength training alone or associated with rGH or nandrolone undecanoate. Eur J Endocrinol 2004;150:511-515.

82 Shah K, Wingkun NJ, Lambert CP, Villareal DT: Weight-loss therapy improves endurance capacity in obese older adults. J Am Geriatr Soc 2008;56:1157-1159.

-83 You T, Berman DM, Ryan AS, Nicklas BJ: Effects of hypocaloric diet and exercise training on inflammation and adipocyte lipolysis in obese postmenopausal women. J Clin Endocrinol Metab 2004;89:1739-1746.

84 Frimel TN, Sinacore DR, Villareal DT: Exercise attenuates the weight-loss-induced reduction in muscle mass in frail obese older adults. Med Sci Sports Exerc 2008;40:1213-1219. 
Mathus-Vliegen et al.: Prevalence, Pathophysiology, Health Consequences and

Treatment Options of Obesity in the Elderly: A Guideline

85 Chomentowski P, Dube JJ, Amati F, Stefanovic-Racic M, Zhu S, Toledo FG, et al: Moderate exercise attenuates the loss of skeletal muscle mass that occurs with intentional caloric restriction-induced weight loss in older, overweight to obese adults. J Gerontol A Biol Sci Med Sci 2009;64:575-580.

-86 Shah K, Stufflebam A, Hilton TN, Sinacore DR, Klein S, Villareal DT: Diet and exercise interventions reduce intrahepatic fat content and improve insulin sensitivity in obese older adults. Obesity (Silver Spring) 2009; 17:2162-2168.

87 Witham MD, Avenell A: Interventions to achieve long-term weight loss in obese older people: a systematic review and meta-analysis. Age Ageing 2010;39:176-184.

$\$ 88$ Weinheimer EM, Sands LP, Campbell WW: A systematic review of the separate and combined effects of energy restriction and exercise on fat-free mass in middle-aged and older adults: implications for sarcopenic obesity. Nutr Rev 2010;68:375-388.

89 Garrow JS, Summerbell CD: Meta-analysis: effect of exercise, with or without dieting, on the body composition of overweight subjects. Eur J Clin Nutr 1995;49:1-10.

$\$ 90$ Haskell WL, Lee IM, Pate RR, Powell KE, Blair SN, Franklin BA, et al: Physical activity and public health: updated recommendation for adults from the American College of Sports Medicine and the American Heart Association. Med Sci Sports Exerc 2007;39:1423-1434.

91 Liu CJ, Latham NK: Progressive resistance strength training for improving physical function in older adults. Cochrane Database Syst Rev 2009;CD002759.

$\$ 92$ Davidson LE, Hudson R, Kilpatrick K, Kuk JL, McMillan K, Janiszewski PM, et al: Effects of exercise modality on insulin resistance and functional limitation in older adults: a randomized controlled trial. Arch Intern Med 2009;169:122-131.

$\$ 93$ Leveritt M, Abernethy PJ, Barry BK, Logan PA: Concurrent strength and endurance training. A review. Sports Med 1999;28:413-427.

$\$ 94$ Leveritt M, Abernethy PJ, Barry B, Logan PA. Concurrent strength and endurance training: the influence of dependent variable selection. J Strength Cond Res 2003;17:503-508.

-95 Lambert CP, Wright NR, Finck BN, Villareal DT. Exercise but not diet-induced weight loss decreases skeletal muscle inflammatory gene expression in frail obese elderly persons. J Appl Physiol 2008;105:473-478.

-96 Villareal DT, Smith GI, Sinacore DR, Shah K, Mittendorfer B: Regular multicomponent exercise increases physical fitness and muscle protein anabolism in frail, obese, older adults. Obesity (Silver Spring) 2011;19: 312-318.

97 Schechtman KB, Ory MG: The effects of exercise on the quality of life of frail older adults: a preplanned meta-analysis of the FICSIT trials. Ann Behav Med 2001;23:186-197.

-98 Netz Y, Wu MJ, Becker BJ, Tenenbaum G: Physical activity and psychological well-being in advanced age: a meta-analysis of intervention studies. Psychol Aging 2005;20:272-284.

$>99$ Kelley GA, Kelley KS, Hootman JM, Jones DL: Exercise and health-related quality of life in older communitydwelling adults. J Appl Gerontol 2009;28:369-394.

100 Yassine HN, Marchetti CM, Krishnan RK, Vrobel TR, Gonzalez F, Kirwan JP: Effects of exercise and caloric restriction on insulin resistance and cardiometabolic risk factors in older obese adults - a randomized clinical trial. J Gerontol A Biol Sci Med Sci 2009;64:90-95.

101 Rejeski WJ, Brubaker PH, Goff DC Jr, Bearon LB, McClelland JW, Perri MG, et al: Translating weight loss and physical activity programs into the community to preserve mobility in older, obese adults in poor cardiovascular health. Arch Intern Med 2011;171:880-886.

102 Sallinen J, Leinonen R, Hirvensalo M, Lyyra TM, Heikkinen E, Rantanen T: Perceived constraints on physical exercise among obese and non-obese older people. Prev Med 2009;49:506-510.

103 Conn VS, Valentine JC, Cooper HM: Interventions to increase physical activity among aging adults: a metaanalysis. Ann Behav Med 2002;24:190-200.

104 Li Z, Maglione M, Tu W, Mojica W, Arterburn D, Shugarman LR, et al: Meta-analysis: pharmacologic treatment of obesity. Ann Intern Med 2005;142:532-546.

105 Bray GA: Medications for obesity: mechanisms and applications. Clin Chest Med 2009;30:525-538, ix.

106 Bray GA, Ryan DH: Drug treatment of the overweight patient. Gastroenterology 2007;132:2239-2252.

107 Padwal RS, Majumdar SR: Drug treatments for obesity: orlistat, sibutramine, and rimonabant. Lancet 2007; 369:71-77.

108 Rucker D, Padwal R, Li SK, Curioni C, Lau DC: Long term pharmacotherapy for obesity and overweight: updated meta-analysis. BMJ 2007;335:1194-1199.

109 Muls E, Kolanowski J, Scheen A, Van Gaal L: The effects of orlistat on weight and on serum lipids in obese patients with hypercholesterolemia: a randomized, double-blind, placebo-controlled, multicentre study. Int J Obes Relat Metab Disord 2001;25:1713-1721.

110 Jacob S, Rabbia M, Meier MK, Hauptman J: Orlistat 120 mg improves glycaemic control in type 2 diabetic patients with or without concurrent weight loss. Diabetes Obes Metab 2009;11:361-371.

111 Hauptman J, Lucas C, Boldrin MN, Collins H, Segal KR: Orlistat in the long-term treatment of obesity in primary care settings. Arch Fam Med 2000;9:160-167.

112 Segal KR, Lucas C, Boldrin M, Hauptman J: Weight loss efficacy of orlistat in obese elderly adults. Obes Res 1999;7(suppl):26A (abstract).

113 Bailey CJ: The challenge of managing coexistent type 2 diabetes and obesity. BMJ 2011;342:d1996. 
114 Amori RE, Lau J, Pittas AG: Efficacy and safety of incretin therapy in type 2 diabetes: systematic review and meta-analysis. JAMA 2007;298:194-206.

115 Vilsboll T, Christensen M, Junker AE, Knop FK, Gluud LL: Effects of glucagon-like peptide-1 receptor agonists on weight loss: systematic review and meta-analyses of randomised controlled trials. BMJ 2012;344:d7771.

116 Sjöström L, Lindroos AK, Peltonen M, Torgerson J, Bouchard C, Carlsson B, et al: Lifestyle, diabetes, and cardiovascular risk factors 10 years after bariatric surgery. N Engl J Med 2004;351:2683-2693.

117 Sjöström L, Narbro K, Sjöström D, Karason K, Larsson B, Wedel H, et al: Effects of bariatric surgery on mortality in Swedish obese subjects. N Engl J Med 2010;357:741-752.

118 NIH Conference. Gastrointestinal Surgery for Severe Obesity. Consensus Development Conference Panel. Ann Intern Med 1991;115:956-961.

119 Fried M, Hainer V, Basdevant A, Buchwald H, Deitel M, Finer N, et al: Interdisciplinary European guidelines for surgery for severe (morbid) obesity. Obes Surg 2007;17:260-270.

120 Sugerman HJ, Demaria EJ, Kellum JM, Sugerman EL, Meador JG, Wolfe LG: Effects of bariatric surgery in older patients. Ann Surg 2004;240:243-247.

121 Sosa JL, Pombo H, Pallavicini H, Ruiz-Rodriguez M: Laparoscopic gastric bypass beyond age 60. Obes Surg 2004;14:1398-1401.

122 St Peter SD, Craft RO, Tiede JL, Swain JM. Impact of advanced age on weight loss and health benefits after laparoscopic gastric bypass. Arch Surg 2005;140:165-168.

123 Abu-Abeid S, Keidar A, Szold A. Resolution of chronic medical conditions after laparoscopic adjustable silicone gastric banding for the treatment of morbid obesity in the elderly. Surg Endosc 2001;15:132-134.

124 Quebbemann B, Engstrom D, Siegfried T, Garner K, Dallal R: Bariatric surgery in patients older than 65 years is safe and effective. Surg Obes Relat Dis 2005;1:389-392.

125 Varela JE, Wilson SE, Nguyen NT: Outcomes of bariatric surgery in the elderly. Am Surg 2006;72:865-869.

126 Dorman RB, Abraham AA, Al-Refaie WB, Parsons HM, Ikramuddin S, Habermann EB. Bariatric surgery outcomes in the elderly: an ACS NSQIP study. J Gastrointest Surg 2012;16:35-44.

127 Maciejewski ML, Livingston EH, Smith VA, Kavee AL, Kahwati LC, Henderson WG, et al: Survival among high-risk patients after bariatric surgery. JAMA 2011;305:2419-2426. 


\section{Erratum}

In the article by Mathus-Vliegen EMH, on behalf of the Obesity Management Task Force (OMTF) of the European Association for Study of Obesity (EASO): Prevalence, Pathophysiology, Health Consequences, and Treatment Options of Obesity in the Elderly: A Guideline. Obes Facts 2012;5;460-483 the following additional information has to be added:

We would like to point out that the contents of the article 'Obesity and the Elderly' by Mathus-Vliegen EMH (J Clin Gastroenterol 2012;46:533-544) were incorporated in this guideline. 